\title{
Polyvagal theory, neurodevelopment and psychiatric disorders
}

\author{
M. O. Huttunen ${ }^{1, *}$ and S. A. Mednick ${ }^{2 *}$ \\ ${ }^{1}$ Department of Mental Health and Alcohol Research, National Institute for Health and Welfare, Helsinki, Finland \\ ${ }^{2}$ Cheltenham Road, Toledo, OH, USA \\ * Passed away April, 2015
}

\begin{abstract}
Neurodevelopment is an area of psychiatry which has attracted huge interest in the last few decades. There is substantial evidence that perinatal events can contribute to later development of mental disorder. In the current perspective article we propose a novel polyvagal theory which attempts to link prenatal events with neurodevelopment and the later onset of psychiatric disorder.
\end{abstract}

Received 28 August 2017; Accepted 30 September 2017; First published online 6 December 2017

Key words: Neurodevelopment, polyvagal theory, psychiatric disorder.

Prenatal infections and stress have been shown to increase the incidence of schizophrenia, affective disorders and autism (Huttunen \& Niskanen, 1978; Mednick et al. 1988; Machón et al. 1997; Cannon et al. 2014). All of these disorders are known be associated with impairments in social relations. We would like to propose a novel mechanism linking the prenatal response to stress and inflammation with the later development of psychiatric disorder.

According to the polyvagal theory (Porges, 2007) the autonomic system consists of three parts - the phylogenetically oldest dorsal parasympathetic or vagal system, the sympathetic system and phylogenetically newest ventral vagal system. These three parts of the autonomic nervous system of mammals play different roles in the evolutionary stress responses in mammals. The myelinated neurons of the ventral vagal system function as a 'brake' for the 'fight-flight' activity of sympathetic nervous system. The unmyelinated dorsal vagal activity takes control if the 'fight/flight' behavior fails to protect the individual, resulting in defensive immobilization - the 'freeze' response.

The efferent pathways of the ventral vagal neurons in the nucleus ambiguus (situated in the medullary reticular formation) are known to innervate muscles of the face, eyelids, larynx, pharynx and middle ear. These regions regulate facial expression, vocal prosody and listening, all of which promote social engagement. Functionally, the ventral vagal system lowers the heart rate, dampens the hypothalamic-pituitary axis, promotes self-soothing behaviors and thus enables the individual to engage with other individuals (Mednick et al. 1988). In this way the extent of

\footnotetext{
* Address for correspondence: M. O. Huttunen, MD, PhD, Department of Mental Health and Alcohol Research, National Institute for Health and Welfare, Helsinki, Finland.

(Email: matti.huttunen@konsmoh.inet.fi)
}

social engagement is dependent on the vagal brake provided by the efferent neurons of nucleus ambiguus.

Developmentally, the number of myelinated vagal fibers increases from 23 to 28 weeks of gestation until birth, when the number of fibers is comparable to those observed in adolescence (Sachis et al. 1982).

Putting these lines of research together, it is proposed that prenatal infections and stress affect the development of myelinated neurons of the ventral vagal system and, by this mechanism, increase the sensitivity of children for traumatic experiences and their risk for major psychiatric disorder. This theory merits research as it could have significant public health implications, and would highlight the critical importance of ensuring adequate medical and psychosocial supports during the perinatal phase.

\section{Acknowledgments}

This perspective piece has been adapted from a previous Finnish publication authored by Professor Matti Huttunen (Respektiä ja rakkautta, ISBN 978-952-571876-8). PROMETHEUS kustannus Oy (ltd) have kindly agreed to grant the right to publish this adapted translation of the book. This piece has been published in honor of Sarnoff Mednick, with whom this idea was developed and discussed a few months before his sad death in April 2015.

\section{Conflicts of Interest}

M.H. has no conflicts of interest to disclose. S.M. has no conflicts of interest to disclose.

\section{Ethical Standards}

The authors assert that all procedures contributing to this work comply with the ethical standards of the 
relevant national and institutional committee on human experimentation with the Helsinki Declaration of 1975 , as revised in 2008.

\section{Financial Supports}

This paper received no specific grant from any funding agency, commercial or not-for-profit sectors.

\section{References}

Huttunen MO, Niskanen P (1978). Prenatal loss of father and psychiatric disorders. Archives of General Psychiatry 35, 429-431.

Mednick SM, Machón RA, Huttunen MO, Bonnet D (1988). Adult schizophrenia following prenatal exposure to an influenza epidemic. Archives of General Psychiatry 45, 189-192.

Machón RA, Mednick SA, Huttunen MO (1997). Adult major affective disorder after prenatal exposure to an influenza epidemic. Archives of General Psychiatry 54, 322-328.

Cannon M, Clarke MC, Cotter DR (2014). Priming the brain for psychosis: maternal inflammation during fetal development and the risk of later psychiatric disorder. American Journal of Psychiatry 171, 901-905.

Porges SW (2007). The polyvagal perspective. Biological Psychology 74, 118-143.

Sachis PN, Armstrong DL, Becker LE, Bryan AC (1982). Myelination of the human vagus nerve from 24 weeks postconceptual age to adolescence. Neuropathology and Experimental Neurology 41, 466-472. 